\title{
Recent studies and prospective application of ohmic heating for fermentation process: a mini- review
}

\author{
Diang Sagita*, Doddy Andy Darmajana, and Dadang Dayat Hidayat \\ Research Center for Appropriate Technology, Indonesian Institute of Sciences, Indonesia
}

\begin{abstract}
This paper provides a mini-review on the utilization of ohmic heating technology in fermentation processes as a new prospect in postharvest and food science technology. Many scientific studies claim ohmic heatingas a novel technology that offers rapid and uniform heating while causing less thermal harm than traditional heating. Ohmic heating also provides high energy efficiency compared to conventional heating. These advantages make ohmic heating widely applied in various processes and gradually applied to the fermentation process for conditioning the optimum temperature. The principles of ohmic heating have already demonstrated scientific advances and there is steady progress in many sectors, including the food sector. Keeping these considerations, the present review describes several scientific studies related to the use of ohmic heating in the fermentation processes and its potential for further research and development. Several studies have reported that there is an effect of using ohmic heating in the fermentation process and has a positive impact on the results of fermented products.
\end{abstract}

\section{Introduction}

Fermentation is one of the oldest food processing techniques. This bioprocessing technique has been used in the chemical, agricultural, and food industries for centuries around the world[1-3]. In developing countries, fermentation is a very popular method for food processing. It acts as an inexpensive and manageable food preservation technique in the absence of home refrigeration, cooling, or canning equipment. Fermentation serves a variety of purposes such as (a) food preservation, (b) providing attractive taste and additional nutritional value to many products, (c) enhancing food safety by removing natural toxins and compounds that aren't required in the product, and (d) preventing the growth of disease-causing microbes [3]. In the past, traditional fermentation techniques were previously focused on trial and error experiences gained by successive generations of food producers. Science and technology have only recently begun to contribute to a better understanding of the fundamental concepts of fermentation, as well as the critical requirements for ensuring the protection, nutritional, and sensory quality of fermented foods [3]. The majority of the fermentation was done in a batch method. Cinar et al.[2]

\footnotetext{
* Corresponding author: diang.sagita@lipi.go.id
} 
claim that even though the batch process is simple to set up and perform, modeling and managing the batch process is difficult. A slight change in working conditions can have an effect on the fermented product's quality and yield. Temperature is one operating variable that has an effect on the quality of the fermentation process [4]. The microbes that may be involved include molds (mycelial fungi), yeasts (unicellular fungi), and bacteria will develop to their full potential if the ideal conditions and temperatures are set and maintained during the fermentation process.

In the context of developing ideal condition for fermentation, there are many studies that have been tried to design a controlled fermentation process equipment called fermenter. However, a warming generator still uses a conventional heater that utilize heat transmission by conduction and convection. This type of heater has not been able to homogenize the temperature of the products, resulting in a poorly regulated fermentation process[5].

A promising technology that produces rapid and uniform heating has continuously investigated by many researchers, namely ohmic heating which its names is derived from Ohm's law [6]. Previously published paper has reported that when compared to traditional heating, ohmic heating has many advantages. First, under some conditions, a mixture of liquid particles may be uniformly heated, evenwhen particulate substances are present, the product does not undergo a significant temperature gradient within itself [7]. Second, the temperature and duration of the heating process could be precisely adjusted or regulated. With this technology, set point temperatures can be reached quickly, and energy conversion efficiencies are very high [8]. When compared to traditional heating, ohmic technology will minimize heating time by 90 percent and save energy by 82 to 97 percent [9]. The energy efficiency was near to 100 percent, and the temperature was distributed uniformly [10].

Generally, the application of ohmic technology has been used for several purposes such as blanching, cooking, pasteurization and sterilization [9,11-13]. The use of ohmic technology in the fermentation process has recently been applied for temperature conditioning at the beginning of the process. The present review describes several scientific studies related to the application of ohmic heating for the fermentation processes and its potential for further research and development.

\section{Ohmic heating principles}

Ohmic heating, also known as Joule heating, is a form of product heating that uses the electrical resistance of heated objects or materials to produce heat [14]. Ohmic heaters operate by passing electrical current through the material or substance being processed, theninternal heat generation occurs from the heated materials. The basic construction of an ohmic heating system consists of a current source and a reactor with electrodes on both sides (Figure 1). Cell vibration causes friction and dissipation in the form of heat energy. This technology had disappeared due to lack of suitable electrode and system for monitoring and controlling, but lately, interest in ohmic heating has been re-glanced due to the increased availability and quality of electrode material [15].

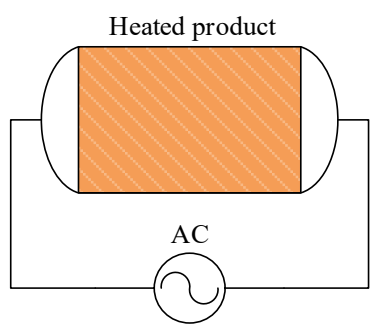

Fig. 1. Basic principles of ohmic heating 
In the ohmic heating system, electrical conductivity (EC) is one of the crucial factors that need to be investigated. EC is a measurement of a material's ability to transmit electric current movements.The electrical conductivity of various materials, especially fruit concentrate (apples, pineapples, pears, strawberries, and peaches), has been reported to range from 0.05 to $1.2 \mathrm{~S} / \mathrm{m}$ (Siemens per meter) $[10,16]$. EC depends on electric current and voltage. Electrical conductivity for any material was calculated by the following equation $[17,18]$.

$$
\sigma=\frac{L}{A} \times \frac{I}{V}
$$

Where, $\sigma$ is electric conductivity $(\mathrm{S} / \mathrm{m}), L$ is the distance between electrodes $(\mathrm{m}), I$ is electric current (A), A is cross-sectional area of product in a reactor fermentor $\left(\mathrm{m}^{2}\right)$, and $\mathrm{V}$ is the voltage $(\mathrm{V})$.

In general, electrical conductivity of products can be measure directly using an EC meter. EC meters are available and many are sold in the market. However, this device is only suitable for liquid products and does not be used for non-liquid or particulate products, thus for any kind of product, Equation 1 can be used to calculate EC even during the heating process occurred.

\section{Ohmic heating design and parameters}

Ohmic heating-based equipment is generally built according to the type of process (batch or continuous) that is applied to the heated material. Some processes such as blanching, pasteurization, sterilization, extraction, fermentation, or waste treatment will have different types of processes, where some need to use the batch type and some must be continuous. Many studies developed ohmic heating equipment, but only a few types of them have been commercialized. This is due to the flexibility of ohmic heating, which cannot be applied easily and the electrodes price is quite expensive. Besides the type of process, there are some of the essential factors that need to be considered in the designing of ohmic heating equipment i.e. electrical properties of the heated products (electrical conductivity), heating rate, voltage gradient, voltage type (AC / DC), frequency \& waveform, electrode type, chamber material, and capacity. An additional feature that must be embedded is a control system that functions to control temperature and electric current.

\subsection{Electrical conductivity}

Electrical conductivity is used as the basis for constructing an ohmic heating system because to utilize the ohmic heating principle, a material must have sufficient electrical conductivity. Pure water has a very low EC value, and it is around $0.055 \mu \mathrm{S} / \mathrm{cm}$, while apple juice is $2.39 \mathrm{mS} / \mathrm{cm}$ and tomato juice is $16.97 \mathrm{mS} / \mathrm{cm} \mathrm{[14].} \mathrm{Thus,} \mathrm{pure} \mathrm{water} \mathrm{is} \mathrm{very}$ difficult to heat using ohmic heating. To increase the EC value, efforts can be conducted by adding electrolytes materials, for example salt $(\mathrm{NaCl})$, which can dissolve into ions in water. This is as occurred in sea water so that sea water has an EC of 55-399.6 (mS / cm) [19].

The electric current that passes through the heating sample causes the sample temperature to rise from $T_{i}$ to $T_{f}$. The heating rate can be calculated by using equation 2 . Then, the amount of heat received by the heated material can be calculated using equation $3[5,20]$. 


$$
\begin{aligned}
& T=\frac{T_{f}-T_{i}}{\Delta t} \\
& Q=\mathrm{m} \times \mathrm{c}_{p} \times\left(T_{f}-T_{i}\right)
\end{aligned}
$$

Where, is heating rate $\left({ }^{\circ} \mathrm{C} / \mathrm{s}\right), T_{f}$ is the final temperature $\left({ }^{\circ} \mathrm{C}\right), T_{i}$ is initial temperature $\left({ }^{\circ} \mathrm{C}\right), \Delta t$ is heating time $(\mathrm{s}), Q$ is heat energy received $(\mathrm{J}), m$ is sample mass heated $(\mathrm{kg})$, and $c_{p}$ is specific heat of the heated sample $\left(\mathrm{J} \cdot \mathrm{kg}^{-1}{ }^{\circ} \mathrm{C}^{-1}\right)$.

\subsection{Voltage gradient}

In an ohmic heating system, the voltage gradient used may affect the heating rate. The SI unit of this parameter is $\mathrm{V} / \mathrm{cm}$. The heating rate increases as the voltage gradient increases, then along with the increase in temperature, the EC will also increase [21]. Commonly the type of voltage used is alternating current (AC). The use of $\mathrm{AC}$ is the most possible, considering that in general the electricity supply in industry is AC.

\subsection{Frequency and waveform}

The next parameter to be considered while developing ohmic heating equipment is frequency \& waveform. The given voltage frequency may affect the EC value during the heating process. Lima et al. [22] reported that a $4 \mathrm{~Hz}$ sawtooth wave can achieve significantly higher drying rates and juice yields than a $60 \mathrm{~Hz}$ sine wave. Another obvious benefit is the higher electrical conductivity of the $4 \mathrm{~Hz}$ sawtooth form, which results in faster heating rates and less pretreatment time than the $60 \mathrm{~Hz}$ sine wave. For general purposes, $50-60 \mathrm{~Hz}$ is usually chosen due to standard available frequency in a country.

\subsection{Electrode}

An electrode is a crucial factor in ohmic heating becausethis part is directly in contact with sample products. Electrodes are typically selected based on price and functionality (resistance and durability), which can have an impact on the ohmic heater's performance.Low carbon electrodes are widely used in applications where product quality is not a concern, such as waste disposal, whereas metals such as stainless steel are ideally suited for food products and similar applications [11]. According to Stancl and Zitny[13], the best electrode is graphite, then followed by TiN and stainless steel.

\subsection{Chamber/container}

Due to the dangers of electricity transmission, materials that can transmit electricity are not permitted to be used in the chamber material for ohmic heating.Plastic, ceramic, glass or something similar (isolator) that cannot transmit electricity is strongly recommended for the ohmic container [5]. In food products, plastics made of polypropylene (PP) are ideal (for low-temperature application) or ceramic/glass material (for high-temperature application). Another material can be selected based on the type of product. For fermentation application, there are several choices of materials due to many types of products that can be fermented, such as yoghurt, cheese, bread, tempeh, soy sauce, cocoa, coffee, etc. For ready to consume products, it is important to choose the best quality chamber material (food grade), but for raw products such as cocoa and coffee that usually fermented in the form of beans, alternative materials can be selected that are easier to find and less costly, such as PE, PVC, wood, or even a clay-based chamber. 


\subsection{Control system}

The additional feature that must be embedded in ohmic heating equipment is a control system. This feature has the function to control the temperature and electric current [5]. Several researchers have tested that the increase in product temperature increases the electrical current due to the change of electrical conductivity in the product $[12,21,23]$. So, to avoid short circuit and electricity overload, the control system regulates the electric current. In system control, it is necessary to have a sensor that detects product temperature, as reference for the control system to regulate electric current. This temperature sensor must be coated with an insulating material so that the sensor readings are not interference by electric currents. Zell et al.[18] developed new rapid response thermocouple probes to monitor temperature changes during ohmic heating. They found that a triple-point probe is the most suitable for ohmic heating applications. The probe is coated by insulating varnish and then fully insulated again with stainless steel sheath.

\section{Ohmic heating effect and efficiency}

Several studies have revealed the effects of ohmic heating on several products. Ohmic heating does not statistically change the chemical composition, $\mathrm{pH}$, lipid oxidation, water holding capacity, or loss of cooking and only slight changes in color and texture [11]. Indrawanet al. [24] were experimenting using ohmic heating for mango juice, and the result was the application of $385 \mathrm{~V}$ voltage in the ohmic reactor can produce the highest energy efficiency up to $94 \%$ and the time required to reach $80{ }^{\circ} \mathrm{C}$ was 130 second. Cho et al. [25] reported that the heating rate of red pepper paste using ohmic heating was about 1.10-3.73 ${ }^{\circ} \mathrm{C} / \mathrm{s}$. Cho et al. [25] also reported that continuous ohmic heat was suitable to sterilize highly viscous products and even better energy efficiency result so it would be suitable for implementation in industrial applications [25]. Another study reported that ohmic heating had been proven to reduce less the loss of carotenoid compounds during heating compared to conventional heating [26]. Nguyen et al. compared the energy efficiency between ohmic heating and microwave heating. They found that ohmic heating efficiency reach $94.2 \%$ while microwave heating only $24.7 \%$. According to Castro et al.[9], ohmic heating, compared to conventional heating, provides more than $82 \%$ energy savings while reducing heating time by around $90 \%$.

Calculation of heating efficiency can be carried out if several parameters are known and observed during the heating process. In general, efficiency is the ratio between the energy used to heat $\left(Q_{\text {out }}\right)$ and the input energy $\left(Q_{i n}\right)$. Energy efficiency in the ohmic heating process can be calculated using equation 4 .

$$
\eta=\frac{m \times e_{p} \times\left[T_{f}-T_{i v}\right)}{E \times I \times \Delta t} \times 100 \%
$$

Where, $\eta$ is heating efficiency (\%), $m$ is sample mass heated $(\mathrm{kg})$, and $c_{p}$ is the specific heat of the heated sample $\left(\mathrm{J}^{\circ} \mathrm{kg}^{-1}{ }^{\circ} \mathrm{C}^{-1}\right) . T_{f}$ is the final temperature $\left({ }^{\circ} \mathrm{C}\right), T_{i}$ is the initial temperature $\left({ }^{\circ} \mathrm{C}\right), E$ is voltage $(\mathrm{V}), I$ is electric current $(\mathrm{A})$, and $\Delta t$ is heating time (s).

\section{Ohmic heating application for fermentation process}

Several recent research have been conducted on the use of ohmic heating technology in the fermentation process for coffee and cocoa products[4,27-30]. 


\subsection{Coffee fermentation}

In the coffee commodity, fermentation is one of the important stages in a series of coffee handling processes. To enable spontaneous or indigenous fermentation to occur, coffee fruits are usually processed using one of three methods immediately after harvesting. The three different types of coffee processing are known as dry, wet, and semi-wet. Fermentation takes a different amount of time depending on the form of processing. The main goal of the fermentation process is to remove the high-polysaccharide (pectin) mucilage layer and reduce the water content of the coffee beans[31]. Besides for that purpose, if the process is properly handled, he fermentation process can also cause chemical reactions that aid in the creation of distinctive coffee bean flavors[32-35]. Tika et al.[36] and Oktadina et al.[37] reported that fermentation can reduce caffeine content on coffee. According to Usman et al.[38] the more extended the fermentation time, the caffeine content, weight of coffee beans and $\mathrm{pH}$ of the liquid fermentation decreases. Low levels of caffeine produce excellent flavour and aroma [37].

Widyotomo and Yusianto [39] reported that fermentation has a real impact on the amount of mucus layer that decompose. The relatively warm space conditions will accelerate the breakdown of sugar during the fermentation process. However, an uncontrolled process will result in a browning reaction, and the implication is the lower flavour. This defect may occur due to the fermentation process goes on uncontrollably. In this case, for conditioning the optimum fermentation temperature, ohmic heating is applied at the beginning of the fermentation process. Reta et al.[40] reported that ohmic technology has a good impact on the fermentedcoffee result. This technology provides fermented coffee, which has a much lower total acidity of $0.18 \%$ (at $30^{\circ} \mathrm{C}$ and 18 hours of fermentation) compared to traditional fermentation. The ohmic assisted fermentation also performed by Reta et al. [4] for the purpose of observing the flavour characteristics of fermented Robusta coffee. With the sensory assessment process, they tried multiple temperature and fermentation time treatments in the hopes of achieving the best coffee flavor. In the treatment of 18 hours fermentation time at a temperature of $35^{\circ} \mathrm{C}$, the flavor profile of Robusta coffee derived from Bantaeng fermented with ohmic fermentation technology is categorized as excellent specialty coffee, with a total score of 83.75 [4]. Another study also reported by [41]. They state that ohmic-assisted fermentation could gain a cupping score ranging from 81.81 to 85.25 with an average cupping score of 84.03. Furthermore, the application of 12 hours fermentation time and $35{ }^{\circ} \mathrm{C}$ temperature generated the highest cupping score of 85.25.

\subsection{Cocoa fermentation}

As in coffee fermentation, fermentation in cocoa also aims to break down mucilage in the beans. Mucilage or pulp, which is rich in moisture and sugars, covers fresh cocoa beans. Candida, Pichia, Saccharomyces, Kloeckera, Trichosporon, and Schizosaccharomyces are some of the yeasts that have been confirmed to play a role in cocoa fermentation [42].

Currently, fermentation technology used for cocoa fermentation in several countries still uses conventional technology. To allow for natural fermentation, cocoa beans are put in containers made of wood, styr ofoam, or bamboo for five to seven days. This method has been documented to produce flavorful cocoa beans. However, the fermentation process using this method usually takes five to seven days, which is quite slow. In fact, by regulating the fermentation conditions, cocoa fermentation can be accelerated and bean flavor quality improved while keeping the majority of the beneficial compounds in the beans [27]. 
Previous research has been conducted by [27] to develop fermenter for controlling temperature by utilizing ohmic principles. Heating is performed during the early stages of fermentation to quickly get the temperature of the beans up to the optimal fermentation temperature. Application of ohmic heating for cocoa fermentation was conducted by Risqan et al. [30]. They claimed to have obtained the highest percentage of fermented cocoa $(96 \%)$ after a 5-day fermentation period at 50 degrees Celsius. Supratomo et al.[27] compared batch fermentation process between traditional and using an ohmic fermenter. It is reported that the use of an ohmic fermenter can speed up the fermentation time where the fermented beans yield by $95 \%$ can be achieved in just three days using the ohmic fermenter, while conventionally need 5-7 days. This phenomenon occurs because ohmic heating will help to shorten the microbial lag phase in the early stages of fermentation by providing the proper temperature for yeast growth [27].

\section{Prospect and potential development of ohmic-based fermenter}

Fermentation is a complex bioprocess. The existence of the necessary ingredients, including the desired microorganism(s) and/or enzyme(s), the required substrates and cofactors, and adequate water, is the principal prerequisite for microbial and enzymatic transformations. In order to provide the transformation to occur, it is necessary to incubate under optimal conditions ( $\mathrm{pH}$, temperature, etc.) for an appropriate period of time[3].

In this context, the use of ohmic technology has been demonstrated to be applicable to a variety of fermentation processes in terms of temperature conditioning to achieve optimal and regulated conditions. Many things can be assessed from the application of ohmic technology to the results of fermented products. The most popular reason for using ohmic applications for fermentation is to find the temperature and time that produces the best product quality, as well as the effect of temperature conditioning at the initial stage of fermentation. Besides, there are still many parameters that may impact on fermented products such as the voltage gradient, frequency and waveform, electrical conductivity, electrode material, and so on. Further tests also need to be conducted to get an ohmic-based controlled fermenter design with a user-friendly control system.

Regarding the prospect of applying ohmic heating for the fermentation process, there are many potential products that can be improved in their fermentation conditions through the application of ohmic heating technology. Table 1 lists several products that usually require fermentation in their production process. 
Table 1. Some products that involve a fermentation process [3]

\begin{tabular}{|c|c|c|}
\hline Name of product & Major ingredient & Functional microorganism \\
\hline Quark & Cows' milk & Lactic acid bacteria (LAB) \\
\hline Yogurt & Cows' milk & LAB \\
\hline Sauerkraut & White cabbage & LAB \\
\hline Cultured milk ("karnemelk") & Cows' milk & LAB \\
\hline Treated black olives & Olives & LAB \\
\hline Gouda cheese & Cows' milk & LAB \\
\hline Raw fermented sausages & Beef meat & LAB \\
\hline Yeast-leavened bread & Wheat flour & Yeasts (Y) \\
\hline Gruyere cheese & Cows' milk & LAB + propionibacteria \\
\hline Pumpernickel bread & Rye flour & LAB + Y \\
\hline Mixed sourdough bread & Rye + wheat flour & LAB + Y \\
\hline Camembert cheese & Cows' milk & LAB + molds \\
\hline Soy sauce & Soybeans and wheat & Molds + LAB + Y \\
\hline Tempeh & Soybeans & LAB + molds + Y \\
\hline Nata de coco & Coconut water & Acetobacter xylinum \\
\hline Fermented cassava ("peuyeum") & Cassava & Y \\
\hline Fermented cocoa bean & Cocoa beans & LAB / Y \\
\hline Fermented coffee bean & Coffee beans & LAB / Y \\
\hline
\end{tabular}

\section{Conclusion}

Several studies have reported that there is an effect of using ohmic heating in the fermentation process and has a positive impact on the results of fermented products. More research into the phenomena and reactions that occur during fermentation using ohmic heating is needed to be studied, especially on products that are commonly fermented. Since it produces a high uniformity of temperature distribution for liquid and non-liquid products, the ohmic heating system has been proven to be important and appropriate for the construction of fermenter equipment.

Acknowledgement. The authors would like to express gratitude to our colleagues at the Research Center for Appropriate Technology - LIPI, who provided valuable input and support to this study.

\section{References}

1. D. M. Pereira, V. T. Soccol, and C. R. Soccol, Curr. Opin. Food Sci. 7, 50-57 (2016).

2. A. Cinar, S. J. Parulekar, C. Undey, and G. Birol, (Marcel Dekker Inc, 2003).

3. M. R. Adams and M. J. R. Nout, (Aspen Publisher Inc, 2001).

4. Reta, Mursalim, J. Muhidong, and Salengke, Int. J. Curr. Res. Biosci. Plant Biol. 4 (7) 33-38 (2017).

5. D. Sagita, D. A. Darmajana, D. D. Hidayat, Novrinaldi, and A. Sitorus, IOP Conf. Ser. Earth Environ. Sci. 542(1), (2020).

6. Y. Q. Kong, D. Li, L. J. Wang, B. Bhandari, X. D. Chen, and Z. H. Mao, Int. J. Food Eng. 4(3) 1-14 (2008).

7. S. C. Eliot-Godéreaux, F. Zuber, and A. Goullieux, Innov. Food Sci. Emerg. Technol. 2, 279-287 (2001).

8. M. Lima, Encycl. Agric. Food, Biol. Eng. 1, 1-3 (2007).

9. I. Castro, J. A. Teixeira, S. Salengke, S. K. Sastry, and A. A. Vicente, Innov. Food Sci. Emerg. Technol. 5, 27-36 (2004). 
10. L. T. Nguyen, W. Choi, S. Hyun, and S. Jun, J. Food Eng. 116 (1) 65-71 (2013).

11. P. Inmanee, P. Kamonpatana, and T. Pirak, LWT - Food Sci. Technol. 108, 183-189 (2019).

12. O. Faruk, S. Sabanci, M. Cevik, H. Yildiz, and F. Icier, J. Food Eng. 207 (4) 1-9 (2017).

13. J. Stancl and R. Zitny, J. Food Eng. 99 (4) 437-444 (2010).

14. M. Sakr and S. Liu, Renew. Sustain. Energy Rev. 39 (2014).

15. H. Poerwanty, Universitas Hasanudin (2018).

16. A. M. Assiry, S. K. Sastry, and C. P. Samaranayake, Bioelectrochemistry 68, 7-13 (2006).

17. A. Assiry, S. K. Sastry, and C. Samaranayake, J. Appl. Electrochem. 33, 187-196 (2003).

18. M. Zell, J. G. Lyng, D. J. Morgan, and D. A. Cronin, J. Food Eng. 93 (3) 344-347 (2009).

19. A. M. Assiry, M. H. Gaily, M. Alsamee, and A. Sarifudin, Desalination. 260 (1) 9-17 (2010).

20. D. D. Hidayat, A. Sudaryanto, Y. R. Kurniawan, A. Indriati, and D. Sagita, INMATEH Agric. Eng. 60 (1) 79-88 (2020).

21. H. Darvishi, J. Saudi Soc. Agric. Sci. 12 (2) 101-108 (2013).

22. M. Lima and S. K. Sastry, J. Food Eng. 41, 115-119 (1999).

23. F. Icier and C. Ilicali, Food Res. Int. 38 1135-1142 (2005).

24. I. C. Adilaksono, B. Susilo, and Y. Sugiarto, J. Teknol. Pertan. 15,2 121-128 (2014).

25. W. Il Cho, E. J. Kim, H. J. Hwang, Y. H. Cha, H. S. Cheon, J. B. Choi, and M. S. Chung, Innov. Food Sci. Emerg. Technol. 42(July), 190-196 (2017).

26. N. Achir, C. Dhuique-Mayer, T. Hadjal, K. Madani, J. P. Pain, and M. Dornier, Innov. Food Sci. Emerg. Technol. 33 397-404 (2016).

27. S. Supratomo, A. Laga, M. Tahir, A. A. Mochtar, and S. Salengke, ARPN J. Eng. Appl. Sci. 14,8 1515-1523 (2019).

28. Reta, Mursalim, Salengke, M. Junaedi, Mariati, and P. Sopade, Food Res. 1,5 157-160 (2017).

29. S. Salengke, A. Hasizah, Reta, and A. A. Mochtar, IOP Conf. Ser. Earth Environ. Sci. 355,1 (2019).

30. Risqan, Salengke, and Iqbal, J. AgriTechno 10,2 180-187 (2017).

31. M. Haile and W. H. Kang, J. Food Qual. 2019, (2019).

32. S. Avallone, J. M. Brillouet, B. Guyot, E. Olguin, and J. P. Gulraud, J. Food Sci. Technol. 37, 191-199 (2002).

33. G. Bytof, S. E. Knopp, P. Schieberle, L. Teutsch, and D. Selmar, Eur. Food Res. Technol. 220, 245-250 (2005).

34. C. Chang Lin, J. Int. Manag. Stud. 5, (2010).

35. R. Redgwel and M. Fischer, Brazilian J. Plant Physiol. 18,1 165-174 (2006).

36. I. N. Tika, N. M. Pujani, and I. G. A. T. Agustiana, "Kandungan kafein pada kopi dengan fermentasi menggunakan mikroba yang diisolasi dari kopi kotoran luwak kebun kopi," in Seminar Nasional Riset Inovatif (2017), pp. 839-846.

37. F. D. Oktadina, B. D. Argo, and M. B. Hermanto, J. Keteknikan Pertan. Trop. dan Biosist. 1,3 265-273 (2013).

38. D. Usman, A. Suprihadi, and E. Kusdiyantini, J. Biol. 4,3 31-40 (2015).

39. S. Widyotomo and Yusianto, Pelita Perkeb. 29,1 53-68 (2013).

40. Reta, Mursalim, Salengke, Junaedi, M. Mariati, and S. P, Food Res. 1,5 157-160 (2017).

41. J. Muhidong and A. Mustafa, Pelita Perkeb. 36,3 226-235 (2020).

42. P. A. Roelofsen, Adv. Food Res. 8, 225-296 (1958). 